unmarried women was not merely an economic or demographic phenomenon, but, instead, 'an index of women's choices'. Indeed, many women, including the Bluestocking writers, Elizabeth Carter and Catherine Talbot, deliberately resisted the institution of marriage, since it would mean the end of their female friendships.

The book succeeds in its main aim to bring to the general reader a wealth of information about seventeenth- and eighteenth-century lesbian culture. This is particularly important for several reasons. By reading her material in such a wideranging and flexible way, Donoghue has supplied us with a substantial body of writings on relationships between women. Not only have these women been given the opportunity to speak in their own voices, but we discover that, far from the silences which were assumed to surround female same-sex relationships, there was in fact a rich language through which this could be communicated. Again, the book points out the necessity of treating lesbian history as unique, rather than looking for exact equivalents of gay men's history. Donoghue thus raises timely and thought-provoking questions about how we 'read' the type of material handed down to us, and takes a stage further the recovery of 'a shared history for all women who love women'.

\section{Rebecca D'Monté}

\section{Gender and Technology in the Making}

Cynthia Cockburn and Susan
Ormrod

London: Sage, 1993

ISBN $803988117 £ 11.95$ Pbk

Why pick this substantive topic: Gender and Microwave Ovens? Why choose this theoretical apparatus to apply to it: Sociology of Technology? Cockburn and Ormrod answer these questions by placing the political agenda right up front: 'In so far as [the book] is about one artifact it is about microwave ovens. But one technology would do as well as another ... It explores some technological processes in order to learn more about the disadvantage of women' (2, my emphasis). But politicians must also attend to more than their moral values. They must address their technological apparatus and choose best where and how to use them.

'Being technologically competent is a badge of masculinity, while the ideal of femininity involves being "hopeless with machines"' says the cover note to the book. By saying 'one technology is as good as another' and treating one theory as good as another, Cockburn and Ormrod are fulfilling their destiny in much the same way as the women they write about in the book.

If you look into the word 'technical', you find its root techne from the Greek which denoted 'skill, art, craft, trade'. A significant strand of Sociology of Technology puts this at the heart of its work to challenge the notion that Technology is something separate from Society. It implies that technologies are integral aspects of ourselves as human subjects as we act and operate in any aspect of our lives. We are brought to life, and bring ourselves to life, through technologies. From this starting point, then, it should come as no surprise to find that technologies in the forms of stereo equipment, cars and microwave ovens are part of the process which produce us as different kinds of beings, the terms woman, man and microwave being three small words available to describe these beings.

My argument here is that this should have been the starting point 
for Cockburn and Ormrod, particularly as they choose to situate themselves in the Sociology of Technology. However, this book demonstrates that they have missed the opportunity, and instead they choose to 'hang around', repeating the complaint that it is 'unfair' to be constituted as a 'woman' in the social structuring of relations which counts for many of our ordinary mundane lives.

Sociology of Technology starts from a simple and powerful question: how is it possible to think of technical things as something quite separate and distinct from social things? This direction of inquiry begins to bring to light the myriad social practices and discourses which are constantly in process of bringing us to life in various forms and in various relationships.

The separation of technology from sociology, for example, is achieved through the discourses and practices of institutional forms which produce us as academics: funding bodies, faculties, departments, syllabi, library categorization schemes, research assessment procedures, etc., etc. These institutional forms, or technologies of knowledge, leave their mark on the substantive areas of study chosen and technologies of investigation (theoretical apparatus) used in these different domains; just as academics are produced in these institutional forms, these technologies, and not just by their 'upbringing'.

Cockburn and Ormrod say of their subjects that they "walk into our microwave story already-women and already-men, bringing with them the effects of a lifetime lived in the family, the street, the school, the shopping precinct, the pub' (6). Whereas this is undoubtedly true, if the question how is not pushed further we could end up assuming that by the time they get to the factory, or the kitchen, the humans are fixed in their identity. All the shaping has been already done. No matter that the authors would want to disagree with this as a description of their stance ('certain things about gender are constant across cultures, however: we can say, for instance, that it is universally a relation and a process' (6)); because they have not attended to the theoretical implications of their beliefs and actions, this is the mess they are continually being caught in. It is not possible to have it all, one cannot claim both Harding and Haraway as equally relevant to the study, one must attend to the implications of the theoretical stances, recognize the capacities of the technologies, if you like, if one wants to be competent and useful in one's cause.

The static theoretic can be seen in the way that the book places its three entities as already given (man, woman, microwave). Rather than asking what produces these three subjects as separate and distinct entities it has assumed that they all already pre-exist the study, and are treated as objects which merely revolve in each others' orbit. The task of the researcher in this world-view is to track the orbit and record the progress. Not to analyse, explain, or offer a way of understanding. The data is presented as if it speaks for itself.

But data doesn't. At the end of the research period, one of the authors (Cockburn) returned to the site and took photographs. She cannot say why these photographs might be important, ('No ambitious claims are made for the photographs from a sociological point of view' (4) but leaves them there for the reader to make sense of. But it still takes the artistry of a skilled reader to make sense from these representations, and it is a competent theoretician who is also able to articulate how they achieve that reading. It is to these skills that we must attend if we are to be anything other than technically incompetent badge-wearing feminists. 